\title{
The Columnar/Equiax Transition in IN718 and Related Alloys
}

\author{
A. Mitchell, S Cockcroft K Takahashi A Schmalz \\ Dept of Metals and Materials Engineering \\ University of British Columbia \\ Vancouver BC Canada V6T 124
}

\begin{abstract}
The columnar/equiax transition (CET) in the solidification structure of both cast and wrought alloys has a strong influence on the properties of the solid alloy through the microsegregation/homogenisation mechanism, It is also important in the control of macrosegregation in the remelting processes. We have investigated the thermal conditions required for the CET, using modified directional solidification techniques and have determined the temperature gradient - solidification rate conditions for the transition. The CET is found to be dependent on both of these variables, leading us to conclude that the fundamental mechanism is that of consitutional undercooling due to solute segregation ahead of the interface. The CET has also been found to be alloy dependent and to be influenced by inclusion concentration in the liquid immediately ahead of the solidifying front.

The results are related to data on the structure of commercial ingots and castings, and are also used to explain the differences in macrostructure observed between ingots of IN 718 processed by VAR, ESR, and EB.
\end{abstract}

Superalloys 718, 625, 706 and Various Derivatives Edited by E.A. Loria

The Minerals, Metals \& Materials Society, 1994 